\title{
Experimental study of an innovative glazed solar air collector tested in real conditions
}

\author{
Andrei-Stelian Bejan ${ }^{1,2^{*}}$, Tiberiu Catalina ${ }^{1,2}$, Daniel Barbu Mocănescu ${ }^{3}$ and Alexandra Ene $^{1}$ \\ ${ }^{1}$ Technical University of Civil Engineering Bucharest, Faculty of Building Services Engineering, 021414 Bucharest, Romania \\ ${ }^{2}$ CAMBI Research Center, 021414 Bucharest, Romania \\ ${ }^{3}$ Neuron Arh Design, 061344 Bucharest, Romania
}

\begin{abstract}
Nowadays, the building sector has a great impact on the $\mathrm{CO} 2$ emissions worldwide being responsible for more than a third of energy consumptions. In order to reduce their impact on the environment it is mandatory to implement renewable energy sources (RES) to produce the so called "green energy". One of the main disadvantages of the systems using RES is the discontinuity in operation and one of the most used RES is the solar radiation which is implemented worldwide and has a great potential to be successfully used. Among the solar systems, solar air collectors (SAC) are systems easy to implement and with low operating costs. For enhancing the overall efficiency of a SAC and to increase the number of hours of operation it is imperative to use thermal energy storage materials (TES). The aim of this paper is to experimentally analyse the implementation of latent heat storage materials (phase changing materials PCM) in glazed solar air collectors and for this purpose two similar collectors were studied in real conditions. After several experimental analysis conducted we have observed that during the night the PCM slowly releases the energy embodied during the daytime and the rise in temperature is higher in $57 \%$ of the time in this case. Moreover the amplitude of outlet temperature variation is lower with $34 \%$ in case of using PCMs.
\end{abstract}

\section{Introduction}

Taking into account the Energy Performance of Buildings Directive implemented within the European Union [1], from 2021 all the new buildings built in the E.U. member countries must be nZEB (nearly zero energy buildings). Moreover, an important part of the energy consumed by the buildings must be covered by systems which are using renewable energy sources.

Nowadays, the buildings sector is responsible for more than $40 \%$ of the energy consumptions worldwide [2] and more than a half of these consumptions are determined by the use of HVAC systems, in order to assure the indoor comfort.

According to the literature, in contrast to the solar water collectors which are better known, solar air collectors have a lower environmental impact [3] and don't have a risk of freezing during the winter. Moreover, these systems have the potential to reduce the energy consumption for heating or preheating the fresh air which is essential in the new, highly sealed buildings, to reduce the energy consumption of heating systems, to reduce the annual operating costs or to improve the efficiency of existent HVAC systems [4-7].

There are several types of solar air collectors $[8,9]$ but mainly, solar air collectors could be classified as: glazed solar collectors and transpired solar collectors.
Glazed solar air collectors (GSC) are recommended because of their efficiency, their higher rise in temperature and reduced operating costs. Moreover, GSCs are independent of weather conditions (wind speed, wind direction, precipitation etc.) because of the glazed cover.

These solar collectors are easy to manufacture, this is why GSCs are the most used air collectors nowadays [6]. From the GSC category, the Trombe walls are the best known systems [8]. Unlike Trombe walls, compact glazed solar collectors could be implemented in order to reduce the space required for the system. Such a collector was studied by Dissa et al. [10] which obtained an exhaust temperature up to $73{ }^{\circ} \mathrm{C}$ and an efficiency up to $61 \%$ for $107{ }^{\circ} \mathrm{C}$ temperature on the metal absorber.

Usually, the glazed solar collectors are without integrated phase changing materials (PCMs) [11]. According to different studies, the integration of thermal mass is mandatory in systems which are using renewable energy sources [12]. In this way, the solar energy could be stored during the periods when solar radiation is available and used during the periods when the additional energy is needed (cloudy periods or during the night).

One of the most promising thermal energy storage materials are the phase changing materials which could store up to 14 times more energy than classical materials $[13,14]$. Organic PCM such as paraffin are the one used

\footnotetext{
* Corresponding author: andrei.s.bejan@gmail.com
} 
in the building sector because of their optimal properties [15].

The glazed solar collector proposed is properly designed in order to contribute to the heating system of a building (reduce energy consumption for heating) by extracting the indoor air which gains thermal energy from the solar radiation. Also, the proposed system could be used in order to preheat the fresh air needed for the building occupants or as an individual collector mounted on the roof. The GSC is made of several layers: glass, air, metal sheet, air gap with airflow obstacles and insulation.

The study aims to analyse the implementation of phase changing materials inside the GSC which have to potential to increase the rise in temperature in the period when solar radiation is not available, to increase the number of hours of functioning with a higher outlet temperature by creating a thermal storage and to improve the resulting temperature variation. For the experimental study, two similar solar collectors were built and studied in real conditions.

\section{Experimental setup}

\subsection{Materials and methods}

In figures 1, 2 and 3 we can observe the glazed solar air collector geometry, functioning and components. Figure 1 shows the cross section of the solar collector with all its layers, figure 2 shows the $1^{\text {st }}$ air layer (with the airflow obstacles) after the air inlet and figure 3 shows the $2^{\text {nd }}$ air layer before the air outlet.

The glazed solar collector has the following dimensions: 1000x600x86 $\mathrm{mm}$ and the inlet/outlet rectangular tubes are $60 \times 30 \mathrm{~mm}$. Outdoor air is introduced in the solar collector using a centrifugal fan positioned on the inlet. The ventilator could not be positioned on the outlet due to its specifications and airflow direction.

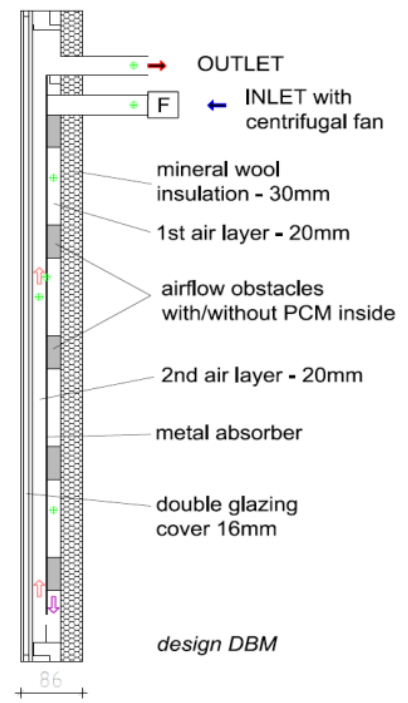

Fig. 1. Glazed solar air collector: geometry, functioning and components.
The nominal flow of the fan is $40 \mathrm{~m}^{3} / \mathrm{h}$, respectively $66 \mathrm{~m}^{3} / \mathrm{h}$ per every square meter of the solar air collector. After entering through the inlet, the air crosses the $1^{\text {st }}$ air layer (20 $\mathrm{mm}$ thick) being preheated by the metal absorber and the airflow obstacles which are used in order to increase the heat transfer surface and to increase the overall efficiency of the solar collector.

After crossing the entire layer, the air is transferred through 26 holes of $15 \mathrm{~mm}$ diameter in the $2^{\text {nd }}$ air layer (20 mm thick air cavity) in which greenhouse effect is created by the double glazing cover (16 mm thick), causing higher values of temperature inside the solar air collector.

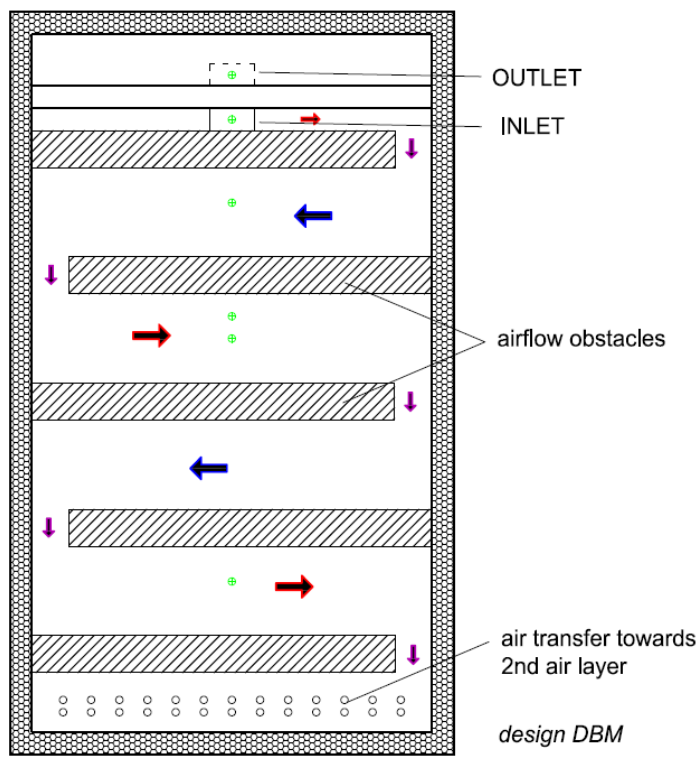

Fig. 2. Back view: $1^{\text {st }}$ layer of air with airflow obstacles.

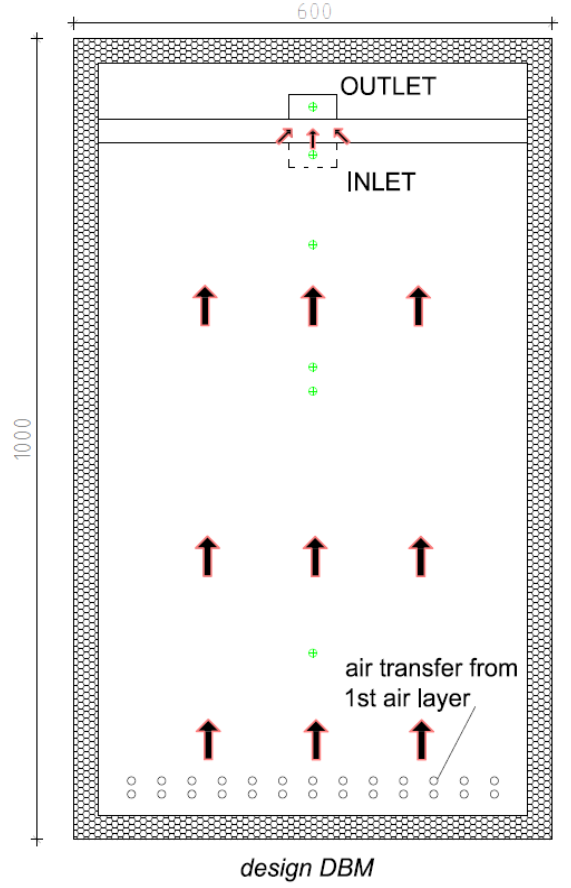

Fig. 3. Front view: $2^{\text {nd }}$ layer of air (cavity). 
The metal absorber was painted in black in order to capture as much solar radiation as possible and all the walls of the solar collector were insulated with $30 \mathrm{~mm}$ of mineral wool in order to minimise the losses. After crossing the two air cavities created in the back and in the front of the solar collector, the air is evacuated through the outlet tube positioned on the upper part of the system.

For the experimental setup two types of solar collectors were studied: with and without integrated phase changing materials. Besides the role of increasing the thermal transfer between the metal absorber and air, the airflow obstacles could be used also as thermal energy storage container.

For this purpose, the airflow obstacles from one of the solar collectors were filled with organic PCM (paraffin) with $55{ }^{\circ} \mathrm{C}$ phase changing temperature (peak value), with the properties presented in table 1 .

Table 1. PCM properties.

\begin{tabular}{|c|c|c|}
\hline Data & Value & Unit \\
\hline Melting area & $50-58$ & ${ }^{\circ} \mathrm{C}$ \\
\hline Solidifying area & $58-51$ & ${ }^{\circ} \mathrm{C}$ \\
\hline Heat storage capacity & 165 & $\mathrm{~kJ} / \mathrm{kg}$ \\
\hline Specific heat capacity & 2 & $\mathrm{~kJ} / \mathrm{kg} \mathrm{K}$ \\
\hline Density solid (at $\left.15^{\circ} \mathrm{C}\right)$ & 0.88 & $\mathrm{~kg} / 1$ \\
\hline Density liquid $\left(\right.$ at $\left.80^{\circ} \mathrm{C}\right)$ & 0.78 & $\mathrm{~kg} / 1$ \\
\hline Heat conductivity & 0.2 & $\mathrm{~W} / \mathrm{m} \mathrm{K}$ \\
\hline
\end{tabular}

In the $1^{\text {st }}$ air cavity there are five airflow obstacles and one obstacle has the following dimensions: $500 \times 50 \times 20 \mathrm{~mm}$, which determines a total volume of PCM inside the solar collector of approximately 2.5 litters in liquid state and 2.22 litres in solid state (approx. $12 \%$ volume variation). In order to cope with the volume changes during the phase change, very small orifices were realised.

\subsection{Measurement procedure}

The two solar collectors were studied in similar outdoor conditions in real time and the measurement procedure is described below. Both collectors were positioned on a building room located in Bucharest, Romania, facing south orientation and with a $60^{\circ}$ inclination (figure 4). The solar collectors were not connected physically to the building because we want to test them later in other applications and in this case they act as building independent systems which could be connected in the future via rectangular ducts. Several experimental studies were conducted and the results presented are for one day which is the most representative for the current analysis (19 $9^{\text {th }}$ June, 2018).

Outdoor conditions were measured using a local meteorological station. The variation of ambient temperature and solar radiation during the day selected from the experimental studies performed is described in figure 5. The maximum value of solar radiation was
$525.7 \mathrm{~W} / \mathrm{m}^{2}$ and the outdoor temperature varied between $20.2{ }^{\circ} \mathrm{C}$ and $34.7{ }^{\circ} \mathrm{C}$. It can be observed that between 12:00 o'clock and 13:45 o'clock there was a short period with certain solar radiation variation (short recurrent periods with clouds).

In order to measure the temperatures in different points of the solar collectors, twelve $\mathrm{NiCr}-\mathrm{Ni} \mathrm{K}$-Type thermocouples were installed, with $\pm 0.2{ }^{\circ} \mathrm{C}$ accuracy: six in the solar collector without phase changing materials and six in the solar collector with PCM integrated in the airflow obstacles.

The positioning of the temperature sensors is emphasised in figure 6 . One sensor is positioned on the inlet $\left(\mathrm{T}_{\text {inlet }}\right)$ in order to measure the precise temperature in that point (which may be slightly different from the ambient temperature), one sensor is positioned on the outlet $\left(\mathrm{T}_{\text {outlet }}\right)$ in order to measure the rise in temperature, one sensor is positioned in the upper part of the $1^{\text {st }}$ air layer $\left(\mathrm{T}_{\text {up }}\right)$, another one is in the downer part $\left(\mathrm{T}_{\text {down }}\right)$ and the last two sensors are on the metal absorber $\left(T_{\text {metal }}\right.$ absorber $)$ and in the $2^{\text {nd }}$ air layer $\left(\mathrm{T}_{\text {cavity }}\right)$.

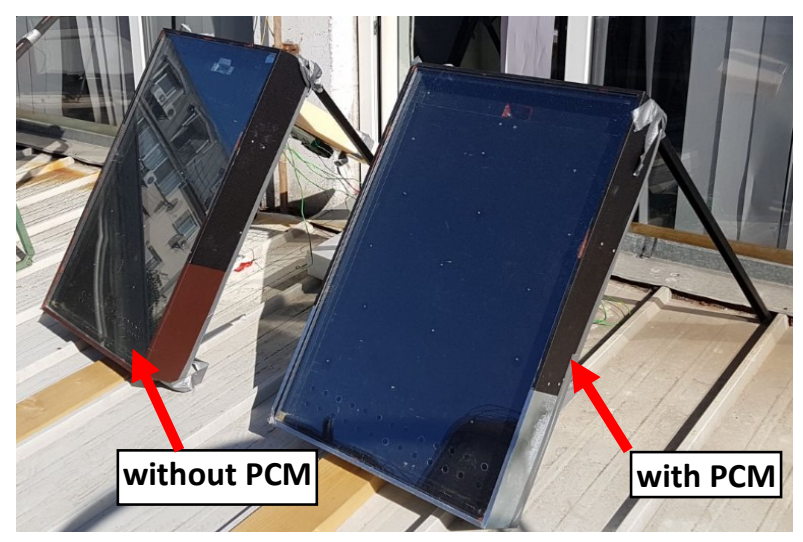

Fig. 4. Experimental setup - positioning of the two solar air collectors on the building roof.

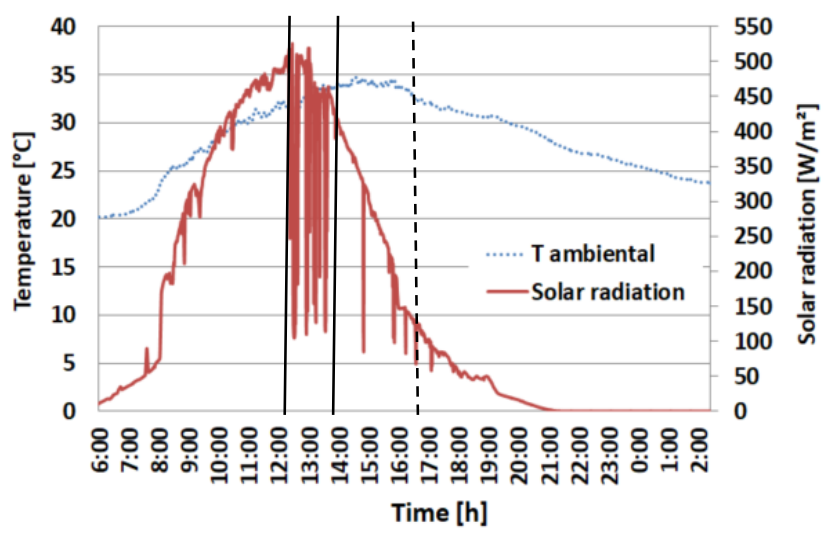

Fig. 5. Meteorological data ( $\mathrm{T}_{\text {ambient }}$ and solar radiation variation during one day) $-19^{\text {th }}$ June, 2018 .

Experimental measurements were performed during multiple days and for the current paper we highlighted 20 hours from the results obtained. Temperature values were recorded every 60 seconds and all the data was collected using an Ahlborn ALMEMO 2890-9 precise data logger. 


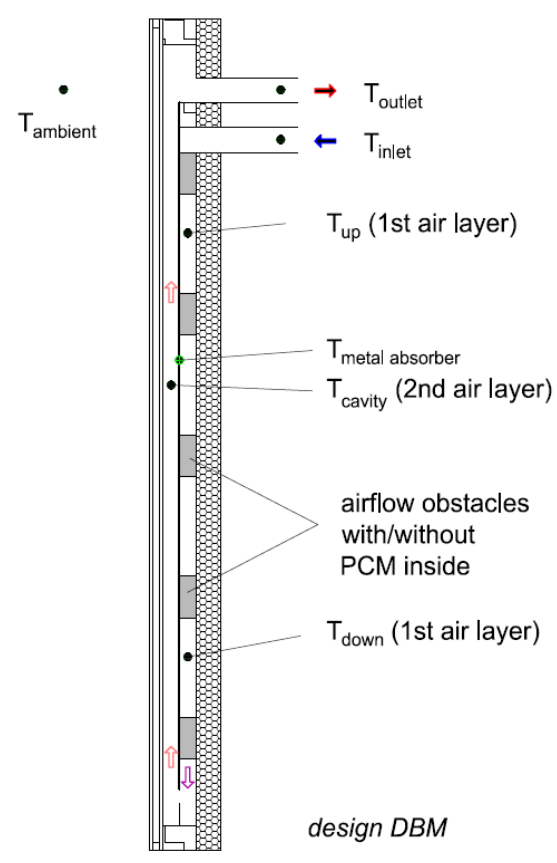

Fig. 6. Temperature sensor positioning.
Following the experimental studies conducted we have obtained very interesting results.

Figure 7 presents the variation of all the temperatures measured in the case of the solar collector without phase changing materials. It can be noticed that after entering the collector the air temperature increases very fast $\left(\mathrm{T}_{\text {up }}\right.$ $-1^{\text {st }}$ air layer). The metal absorber has the highest temperature while the maximum air temperature is reached in the $2^{\text {nd }}$ air layer, inside the cavity between the double glazing and metal sheet because of the greenhouse effect, values which are most of the time equal with the outlet air temperature. All other temperatures $\left(\mathrm{T}_{\text {down }}\right.$ and $\left.\mathrm{T}_{\text {outlet }}\right)$ have similar variations and values and the outlet temperature reaches, during this specific day, a maximum of $82.7^{\circ} \mathrm{C}$.

Figure 8 presents the variation of all the temperatures measured in the case of the solar air collector with phase changing materials macroencapsulated in the airflow obstacles. In the period when the solar radiation is available, the temperature of the metal absorber increases and the PCM begins to melt thus extracting latent heat from the airflow. This phenomenon can be observed also in figure 13.

\section{Results}

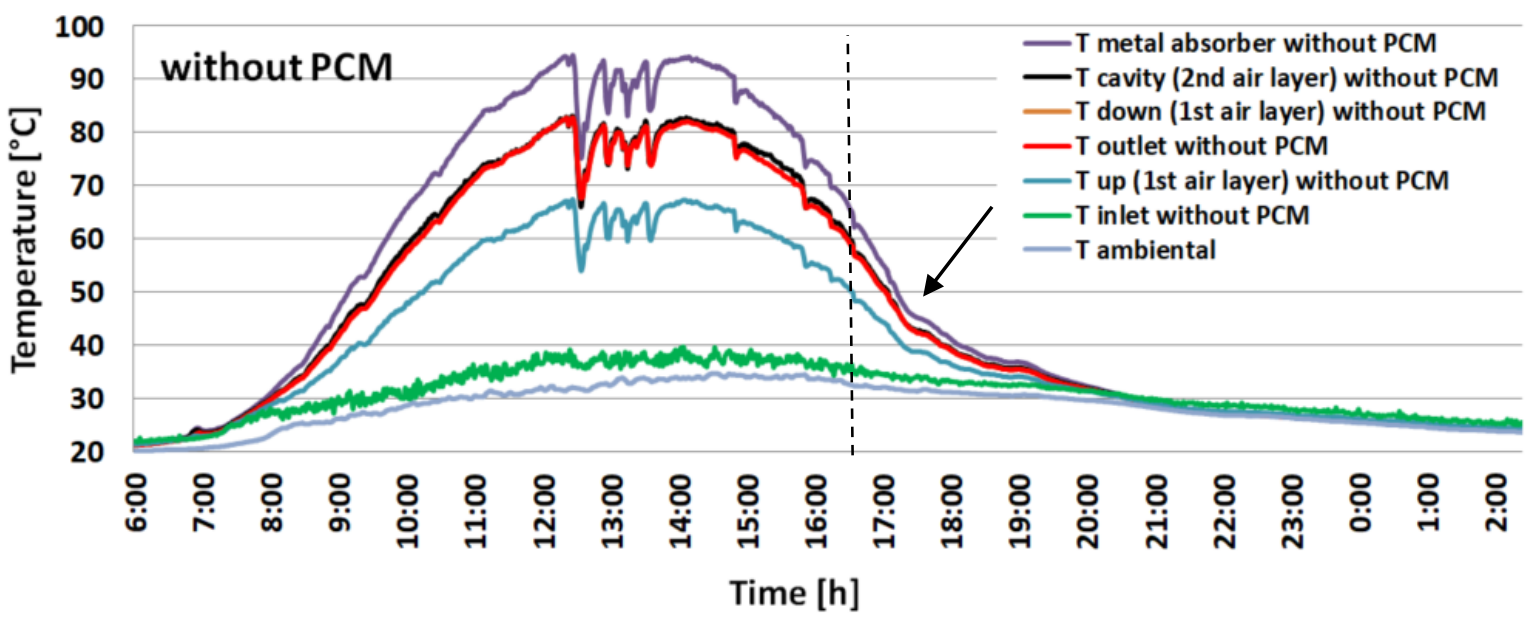

Fig. 7. Variation of the measured temperatures - solar collector without PCM.

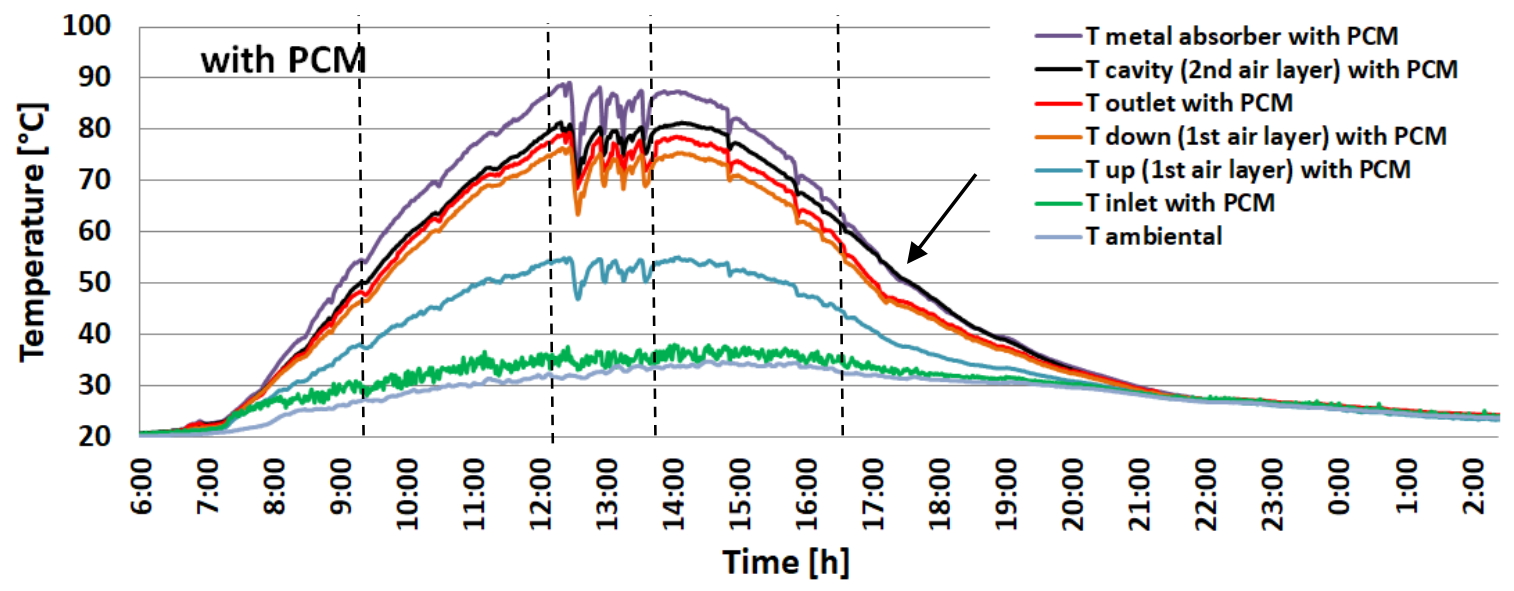

Fig. 8. Variation of the measured temperatures - solar collector with PCM. 
The temperatures variations are similar with the previous case. After entering the collector the airflow gains a lot of energy.

The maximum temperature is reached also in the $2^{\text {nd }}$ air layer. All the three temperatures $\left(\mathrm{T}_{\text {cavity }}, \mathrm{T}_{\text {outlet }}\right.$ and $\mathrm{T}_{\text {down }}$ ) have similar variation until around 09:30 o'clock when the $50{ }^{\circ} \mathrm{C}$ temperature is reached and the PCM begins to melt. From this point the values are different in contrast with the previous case because of the PCM impact. The temperature inside the $2^{\text {nd }}$ air cavity is higher than the outlet temperature in the case of GSC with PCM during the melting period because the PCM is extracting the energy mainly in the upper part of the solar collector, as explained bellow (figure 9).

The maximum outlet temperature reached during the day was $79.3{ }^{\circ} \mathrm{C}$. After $16: 30 \mathrm{pm}$ when the ambient temperature decreases faster, the $58{ }^{\circ} \mathrm{C}$ temperature is reached and the PCM begins to solidify. After this moment, the airflow temperature in the cavity $\left(2^{\text {nd }}\right.$ air layer), after crossing al the PCM obstacles is similar to the temperature measured on the metal plate (unlike the previous case), which means that the PCMs are releasing the energy.

Moreover, by analysing the two figures above we can observe that after 16:30 pm the temperature values are dropping much faster in the case without PCMs, but in the case with PCMs, the decrease is smoother. Also, during the cloudy period (12:00-13:40) when the solar radiation varies, the amplitude of outlet temperature variation is lower with $34 \%$ in case of using phase changing materials.

Figure 9 emphasise the temperature variation in the upper part of the $1^{\text {st }}$ air layer after crossing the first airflow obstacle with and without phase changing materials integrated. We can observe that in this specific point the airflow gains a lot of energy (e.g. at 12:30 pm, the temperature rises from $32.7^{\circ} \mathrm{C}$ ambient temperature to $67.4{ }^{\circ} \mathrm{C}$ in the case without $\mathrm{PCM}$, respectively $55.1{ }^{\circ} \mathrm{C}$ in the case with PCM). Moreover, the effect of PCM melting is the most obvious in this point during the day when the energy is stored. The rise in temperature between $\mathrm{T}_{\text {up }}$ and $\mathrm{T}_{\text {ambient }}$ is $22.4^{\circ} \mathrm{C}$ in the case with PCM and $34.7{ }^{\circ} \mathrm{C}$ in the case without PCM which means 55\% more.

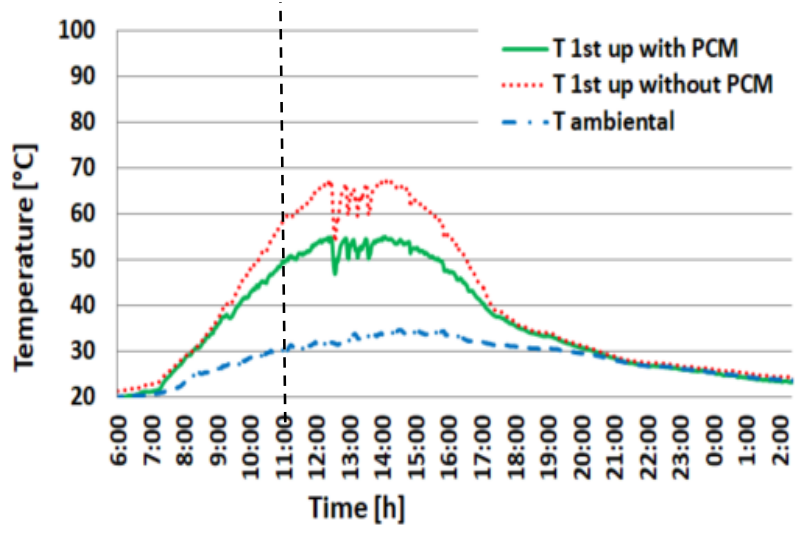

Fig. 9. 1st air layer upper part temperature variation with/without PCM ( $\mathrm{T}_{\text {up }} 1^{\text {st }}$ air layer).
In figure 10 we can observe the temperature variation in the downer part of the $1^{\text {st }}$ air layer after airflow crosses all the five obstacles and the entire back face of the metal absorber. We can observe that in both cases the variations are slightly the same until the melting begins. After this moment the $T_{\text {down }}$ temperature sensor records lower values for the case with PCM because the material begins to store energy. The maximum temperature reached for the case without $\mathrm{PCM}$ is $82.7^{\circ} \mathrm{C}$, while in the case with $\mathrm{PCM}$ is $76.5^{\circ} \mathrm{C}$

An interesting switch of the phenomena begins at 16:30 when the temperature inside drops below the phase change temperature and the PCMs begin to release slowly the embodied energy.

After this moment, $\mathrm{T}_{\text {down }}$ temperature sensor measures higher values for the case with PCM until the end of the measurement procedure, during discharging/night time (540 minutes). The temperature at the bottom of the $1^{\text {st }}$ air layer is higher during discharge period in the case with PCM with values which are varying from $0.2{ }^{\circ} \mathrm{C}$ to $3.7^{\circ} \mathrm{C}$. The impact of PCM discharging is highly visible from 17:00 pm until 19:3 pm.

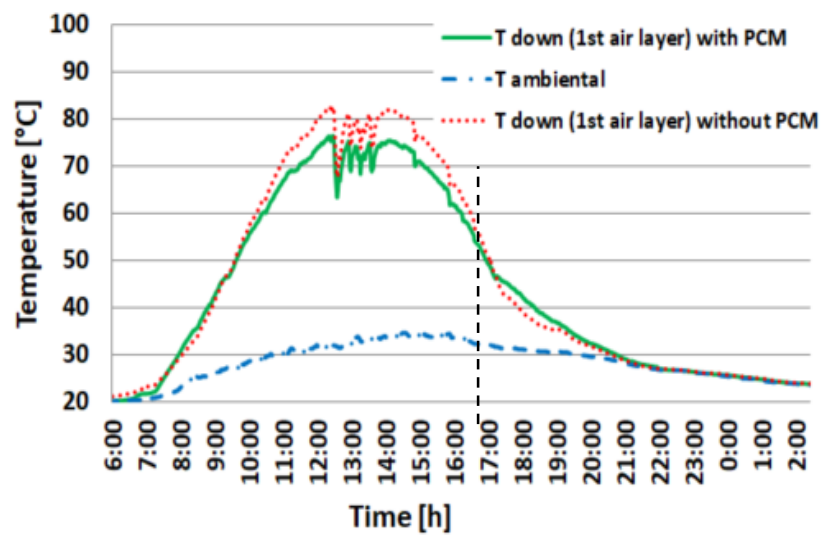

Fig. 10. 1st air layer down part temperature variation with/without PCM (T Town $^{\text {st }}$ air layer).

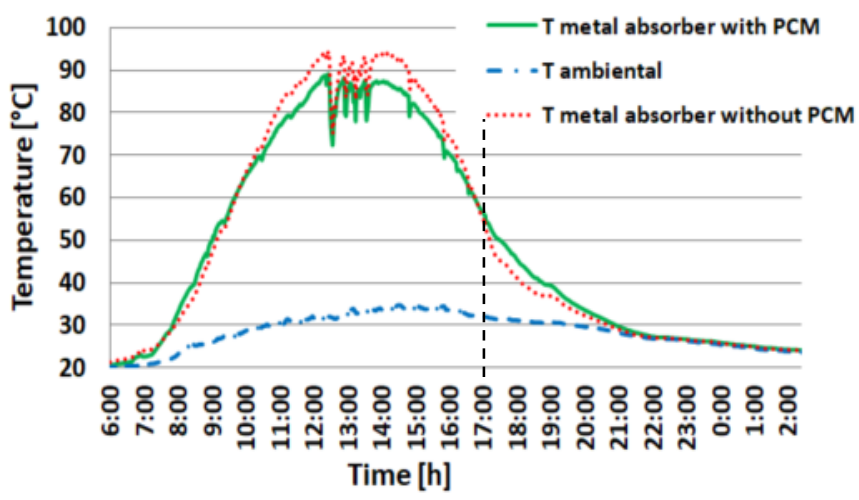

Fig. 11. Metal absorber temperature variation with/without PCM ( $\left.\mathrm{T}_{\text {metal absorber }}\right)$.

Figure 11 presents the temperature variation in the middle of the metal absorber. We can assume that the value is relative constant on the entire surface taking into account the high conductivity of the metal sheet. 
During the day the absorber temperature is lower in the case of solar collector with PCM because the PCMs are storing the energy and after 17:10 pm the metal temperature is higher until the end of the measurements (530 minutes) with values which vary from $0.1{ }^{\circ} \mathrm{C}$ to 4 ${ }^{\circ} \mathrm{C}$, during the discharging period when PCMs are releasing the energy slowly.

Figure 12 emphasise the temperature variation inside the cavity created between the double glazing and metal absorber ( $2^{\text {nd }}$ air layer). In this zone the airflow reaches the highest temperature in the whole system: up to 82.5 ${ }^{\circ} \mathrm{C}$ in the case without PCMs and up to $81{ }^{\circ} \mathrm{C}$ in the case with PCM. During the period when solar radiation is available the temperature values and variation are very similar and the main differences are during the discharge period.

After 16:30 o'clock the temperature inside the cavity is higher in the case of solar collector with PCM until the end of the measurements (570 minutes) with values which vary from $0.1^{\circ} \mathrm{C}$ to $8.8^{\circ} \mathrm{C}$, during the discharging period when PCMs are releasing the energy slowly. The impact of PCM discharging towards the $2^{\text {nd }}$ air cavity is highly visible from 16:40 until 20:30.

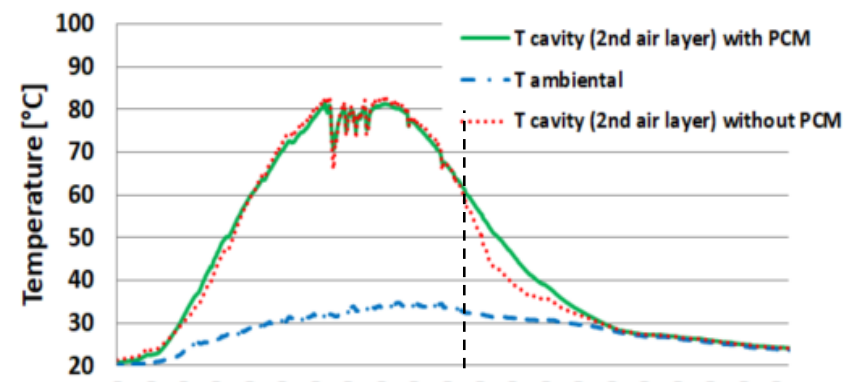

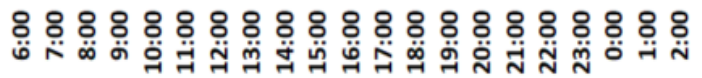

Time [h]

Fig. 12. Cavity ( $2^{\text {nd }}$ air layer) temperature variation with/without $\mathrm{PCM}\left(\mathrm{T}_{\text {cavity }} 2^{\text {nd }}\right.$ air layer $)$.

Figure 13 presents the most relevant parameter of solar collector, respectively the variation of rise in temperature between the inlet and outlet of the solar collectors in both cases, with and without embodied phase changing materials. In $57 \%$ of the time the rise in temperature is higher in case of using PCM.

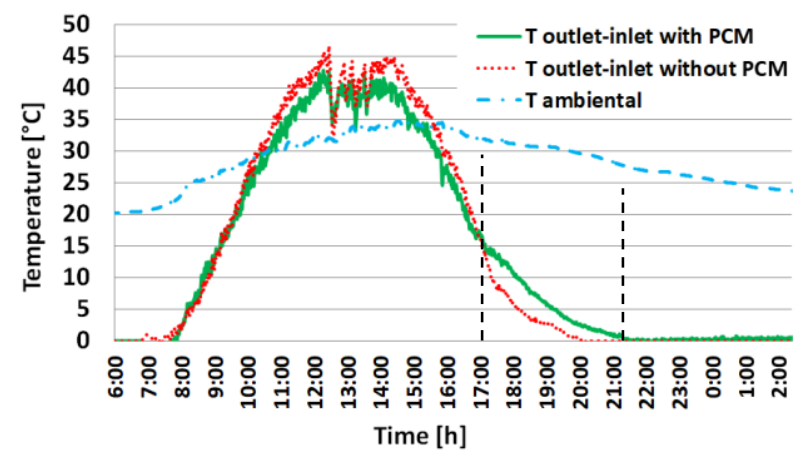

Fig. 13. Rise in temperature between inlet and outlet with/without PCM (Toutlet - Tinlet).
During the day the PCM lowers the exhausted air temperature. The highest rise in temperature is up to $46.7^{\circ} \mathrm{C}$ in the case without PCM and $42.2^{\circ} \mathrm{C}$ in the case with PCM (because of the charging process). After 17:00 o'clock when the solar radiation has a low value and the temperature inside the cavity became lower than the solidifying point (because the ambient temperature also dropped), the rise in temperature is becoming higher in the case with PCM for the rest of the experimental measurements (540 minutes) thus increasing the collectors' number of hours of functioning with a higher outlet temperature. The biggest difference between the two cases is at 17:54, when the rise in temperature in the case of solar collector with PCM is higher with up to 5.3 ${ }^{\circ} \mathrm{C}$ than the case without PCM, which means $82 \%$ more (the rise in temperature in the case of GSC with PCM is $11.7{ }^{\circ} \mathrm{C}$, unlike the case without PCM when the rise in temperature is $6.4{ }^{\circ} \mathrm{C}$ ). Furthermore, from this figure we can observe that the PCM impact is very visible during the first four hours of discharging and also that during discharging period, the PCM releases the energy very slow. Moreover, as we mentioned in the beginning of the chapter, according to figure 8 and figure 13 we can notice that during the cloudy periods the variation of outlet temperature is enhanced by $34 \%$.

\section{Conclusions}

After the experimental studies conducted regarding the implementation of phase changing materials within the glazed solar air collectors very interesting conclusions can be made. The papers aim to evaluate in an experimental manner two different solar air collectors, one simple, without latent heat storage and one with paraffin macroencapsulated in the airflow obstacles installed in the $1^{\text {st }}$ air cavity.

As a result of experimental analysis we can conclude the following:

- In both cases, after entering the collector the air temperature increases very fast $\left(\mathrm{T}_{\mathrm{up}}-1^{\text {st }}\right.$ air layer $)$ and the maximum temperature is reached in the $2^{\text {nd }}$ air layer

- The PCMs are storing a lot of energy in the first part of the solar collector $\left(T_{\text {up }}-1^{\text {st }}\right.$ air layer) and releases it mainly in the second part of the solar collector $\left(\mathrm{T}_{\text {cavity }}-\right.$ $2^{\text {nd }}$ air layer).

- In case of using PCM, during the day the rise in temperature is lower because of the latent heat stored and during the periods when solar radiation isn't available the rise in temperature is higher.

- The energy is released slowly (for further studies we need to enhance the thermal transfer of PCM or to use one with a higher conductivity otherwise the melting-solidifying cycle will not happen entirely)

- After 16:30 the temperature values are dropping very quickly in the case without PCMs, but in the case with PCMs, the decrease is smoother

- In the case of solar collector without PCM the maximum outlet temperature is $82.7{ }^{\circ} \mathrm{C}$ and in the case of solar collector with PCM the maximum outlet temperature is $79.3{ }^{\circ} \mathrm{C}$ 
- During the cloudy period (12:00-13:45) when the solar radiation varies, the amplitude of outlet temperature variation is lower with $34 \%$ in case of using phase changing materials

- The charging phenomena is obvious in the upper part of the $1^{\text {st }}$ air layer while the discharging phenomena is obvious in the downer part of the $1^{\text {st }}$ air layer the $2^{\text {nd }}$ air layer

- In $57 \%$ of the time the rise in temperature is higher in case of using PCM

- After 16:30 o'clock when the solar radiation has a low value and the temperature inside the cavity became lower than the solidifying point (because the ambient temperature also dropped), the rise in temperature is becoming higher in the case with PCM for the rest of the experimental measurements (540 minutes)

- The rise in temperature in the case of solar collector with $\mathrm{PCM}$ is higher with up to $5.3{ }^{\circ} \mathrm{C}$ than the case without PCM, which means $82 \%$ more.

Further studies will be conducted in order to better understand the impact of PCMs. Other types and quantities of PCMs must be used and tested on longer periods. Also, further studies will be made in permanent regime in controlled conditions and in order to assess the global efficiency of the solar air collector by combining it with the building systems.

\section{References}

1. EU, in European Parliament, Council of the European Union. 2010.

2. UNEP, Buildings and Climate Change Summary for Decision-Makers. United Nations Environment Programme - Sustainable Buildings \& Climate Initiative. 2009.

3. C. Reichl, K. Kramer, C. Thoma, P. Benovsky, and T. Lemée, Solar Energy, 120 450-463 (2015).

4. M.A. Leon and S. Kumar, Solar Energy, 81 (1), 6275 (2007).

5. T. Zhang, Y. Tan, X. Zhang, and Z. Li, Building and Environment, 98 158-179 (2016).

6. F.M. Rosaria Ciriminna, Mario Pecoraino, Mario Pagliaro, Energy Technology, 5 1-9 (2017).

7. T. Zhang, Y. Tan, H. Yang, and X. Zhang, Applied Energy, 165 707-734 (2016).

8. K. Hami, B. Draoui, and O. Hami, Energy, 39 (1), 11-16 (2012).

9. A. Shukla, D.N. Nkwetta, Y.J. Cho, V. Stevenson, and P. Jones, Renewable and Sustainable Energy Reviews, 16 (6), 3975-3985 (2012).

10. A.O. Dissa, S. Ouoba, D. Bathiebo, and J. Koulidiati, Solar Energy, 129 156-174 (2016).

11. M.M. Alkilani, K. Sopian, M.A. Alghoul, M. Sohif, and M.H. Ruslan, Renewable and Sustainable Energy Reviews, 15 (3), 1476-1490 (2011).

12. C. Arkar, T. Šuklje, B. Vidrih, and S. Medved, Applied Thermal Engineering, 95 281-287 (2016).
13. N. Soares, J.J. Costa, A.R. Gaspar, and P. Santos, Energy and Buildings, 59 82-103 (2013).

14. A. Kylili and P.A. Fokaides, Journal of Building Engineering, 6 133-143 (2016).

15. T. Khadiran, M.Z. Hussein, Z. Zainal, and R. Rusli, Renewable and Sustainable Energy Reviews, 57 916-928 (2016). 